\section{EN TORNO A LOS DETECTIVES SALVAJES DE ROBERTO BOLAÑO}

\author{
CARMEN DE MORA
}

Universidad de Sevilla, España

demora@us.es

Carmen de Mora

Catedrática de literatura hispanoamericana en la Universidad de Sevilla. Es autora de numerosas publicaciones sobre narrativa hispanoamericana contemporánea relato breve y literatura Colonial. Entre sus libros figuran: Teoría y práctica del cuento en Cortázar (1982), Las siete ciudades de Cíbola. Textos y testimonios sobre la expedición de Vázquez Coronado (1992), En breve. Estudios sobre el cuento hispanoamericano contemporáneo (2 ${ }^{\mathrm{a}}$ ed. 2000) y Escritura e identidad criollas. El Carnero, Cautiverio feliz $e$ Infortunios de Alonso Ramírez (2010). Es editora de Nuevas lecturas de La Florida del Inca (2008) y Humanismo, mestizaje y escritura en los Comentarios reales (2010).

\title{
RESUMEN
}

En el presente artículo se examinan algunas cuestiones fundamentales de la obra de Bolaño en general y de Los detectives salvajes, en particular: el lugar que ocupa el escritor en la narrativa hispanoamericana de los últimos años; la estructura tripartita de la novela con las peculiaridades espaciales y las alteraciones cronológicas que presenta; la proyección autobiográfica y el mito de la vida artística; y el género policial como «architexto» de la novela. Por último, se profundiza en aspectos compositivos de Los detectives salvajes que tienen que ver con las razones que mueven la escritura postdictatorial de Bolaño.

Palabras clave: Roberto Bolaño, Los detectives salvajes, narrativa chilena última, novela policial.

\section{ABSTRACT}

This contribution examines some fundamental aspects of Bolaño's works in general and of Los detectives salvajes, especially: the writers' place in current Hispanoamerican narrative; the tripartite structure of the novel with its spatial particularities and chronological alterations; the autobiographical projections and the myth of artistic life; and the detective story as the novel's «architext». Lastly, the article goes more deeply into some compositional aspects which are connected with the motivations of Bolaño's post-dictatorial writing.

Keywords: Roberto Bolaño, Los detectives salvajes, current Chilean narrative, detective novel.

\section{Introducción}

Como se sabe, Roberto Bolaño (Los Ángeles, Chile, 1953-Barcelona, 2003) empezó a ser un escritor reconocido y de extraordinario éxito a raíz de la publicación de Los detectives salvajes en 1998, obra con la que ganó en España el premio Herralde de novela y con la que obtuvo el Premio Rómulo Gallegos, el más prestigioso que se concede en Hispanoamérica. Consiguió también el del Consejo Nacional del libro y del Círculo de Críticos de Arte de Chile. Antes de publicarla, ya había sacado a la luz otras dos obras importan- tes: La literatura nazi en América y Estrella distante, ambas de 1996.

Entre las generaciones más recientes de escritores latinoamericanos, Bolaño se ha convertido en un referente, sobre todo desde que a partir de la década de los noventa su obra llegó a un considerable número de lectores. Este reconocimiento se materializó en el Encuentro de Autores Latinoamericanos promovido por la Editorial Seix Barral -más exactamente, por Adolfo García, director del sello- y celebrado en la sede de la Fundación Lara, que tuvo lugar en Sevilla, en junio de 2003, cuando apenas le quedaban a Bolaño

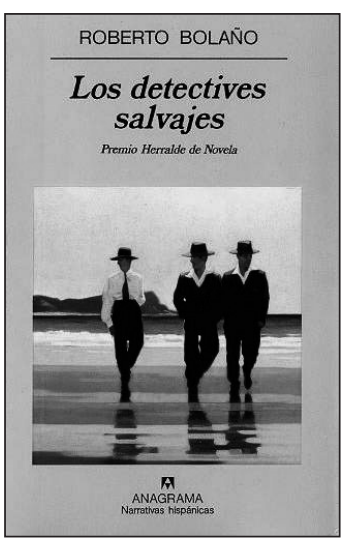

Cubierta Los detectives salvajes.
En torno a Los detectives salvajes $\mathrm{de}$ Roberto Bolaño

CARMEN DE MORA 


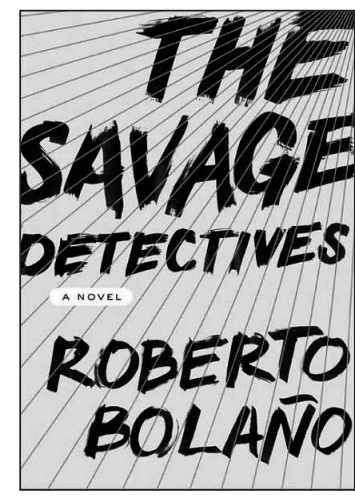

Edición en inglés de Los detectives salvajes.

El temido agente literario Andew Wylie, El Chacal, se ha hecho con algunos inéditos de Bolaño, entre ellos, la novela El Tercer Reich y Los sinsabores del verdadero policía, publicadas en 2010 y 2011 respectivamente.

2

Algunos conocidos suyos han negado tal experiencia y también que estuviera en Chile cuando ocurrió el golpe. Sin duda, el mismo Bolaño fomentó la mitificación de su biografía a sabiendas de que podía resultar un complemento de su literatura con cierto atractivo para los lectores.

3

Entre las leyendas que circulan en Estados Unidos sobre su biografía está la de su adicción a la heroína que supuestamente le habría provocado una enfermedad hepática irreversible.

4

Él escribió con Antoni García Porta Consejos de un discípulo de Morrison a un fanático de Joyce (1984).

En torno a Los detectives salvajes de Roberto Bolaño

CARMEN DE MORA unos días de vida. Algún episodio de aquel encuentro ha sido recreado por Volpi en su libro de ensayos Mentiras contagiosas (2008). En él participaron, además de Bolaño: José María Conget, Jorge Franco, Rodrigo Fresán, Santiago Gamboa, Gonzalo Garcés, Fernando Iwasaki, Mario Mendoza, Ignacio Padilla, Cristina Rivero Garza, Edmundo Paz Soldán, Iván Thays y Jorge Volpi. Las Actas de aquella reunión se publicaron con el título de Palabra de América (Editorial Seix Barral y Fundación José Manuel Lara, Barcelona, 2004), prologadas por Guillermo Cabrera Infante, con epílogo de Pere Gimferrer. Al debatir sobre la identidad de la literatura latinoamericana actual y las nuevas generaciones llegaron a la conclusión de que Borges era tal vez el escritor más fecundo e influyente del siglo pasado para las letras hispanas actuales y que el más influyente de la actualidad era Bolaño, el que estaba abriendo caminos nuevos.

La fama y el éxito del escritor chileno han trascendido las fronteras de habla hispana. ¿Cómo se explica el fenómeno Bolaño? ¿Qué factores han determinado que se haya convertido en un escritor de culto a nivel internacional? No cabe duda de que el mundo editorial y los medios han jugado un papel en la canonización del escritor ${ }^{1}$.

La lectura que se ha hecho en Estados Unidos de la obra de Bolaño es muy distinta a la europea, según ha explicado Sarah Pollack, profesora de la City University de Nueva York, al examinar el fenómeno Bolaño en el mercado editorial norteamericano en su artículo «Latin America Translated (Again): Roberto Bolaño's The Savage Detectives in the United States». La autora encuentra detrás de la construcción del mito Bolaño tanto un operativo de marketing editorial como una redefinición de la imagen de la cultura y la literatura latinoamericanas que se ha difundido entre el público lector. Este fenómeno se produjo cuando Jonathan Galassi, editor jefe de la estadounidense Farrar, Straus \& Giroux (FSG), una de las firmas más selectas del mundo editorial neoyorkino, publicó la versión en inglés de Los detectives salvajes con el título de The Savage Detectives, en 2007. Las obras anteriores a esta se habían publicado en una prestigiosa editorial independiente y minoritaria, New Directions. No obstante, como Pollack demuestra en su ensayo, el éxito de Los detectives salvajes en Estados Unidos iba acompañado de una imagen reduccionista de la novela acorde con las expectativas de los lectores americanos: de un lado, la rebeldía idealista de la juventud y la afición por la poesía, identificada con los 70; de otro, las consecuencias morales que se desprenden de llevar tales actitudes hasta sus últimas consecuencias, pues casi todos los personajes desaparecen o terminan de forma trágica (Pollack, 2009, p. 361). También la prestigiosa escritora Susan Sontag contribuyó al éxito de su recepción cuando sentenció: «Bolaño es el más influyente y admirado novelista en lengua española de su generación» (Manzoni, Gras, Brodsky, 2005, p. 72).

Además de los conocimientos enciclopédicos que poseía en lo referente a literatura y cine, las circunstancias personales de Bolaño sin duda jugaron un papel: la vida azarosa que llevó durante años, la experiencia que vivió en la cárcel cuando le sorprendió en Chile². donde se encontraba de paso, el golpe militar, la relación de algunas de sus obras con el subgénero de las novelas de las dictaduras del Cono Sur, la grave enfermedad que padecía y la muerte a los cincuenta años, todo ello ha repercutido en la dimensión internacional de su figura y en la imagen de Bolaño que se ha querido vender en Estados Unidos ${ }^{3}$ : la del joven contestatario, idealista y rebelde de los años infrarrealistas; de ahí que la foto del escritor que aparecía en la edición norteamericana fuera una de juventud, con melena y aspecto hippie, y no la del hombre maduro y responsable que era cuando la escribió. En la prensa se le comparó con James Dean, Kurt Cobain, Jim Morrison ${ }^{4}$ o Jack Kerouac. Con el añadido de que la crítica, probablemente inducida por el propio Bolaño, ha encontrado en el chileno el digno sucesor de los escritores del Boom, pues tras el agotamiento del realismo mágico, cuyo paradigma está representado por la literatura de García Márquez, los mercados demandaban un producto que ofreciera una imagen nueva de la literatura latinoamericana. Y es ahí donde Bolaño, al menos por ahora, con el «realismo visceral» ha llegado a cubrir un vacío. En efecto, la transformación del infrarrealismo en «realismo visceral» -expresión que evoca y rechaza al mismo tiempo el «relismo mágico»- así como su instalación en Barcelona, sede editorial del «Boom», invitan a pensar que Bolaño era muy consciente del espacio que se estaba disputando en el campo literario latinoamericano. 


\section{Los detectives salvajes (1998)}

Extensa y muy ambiciosa, es una novela de 609 páginas, que recuerda los grandes proyectos novelísticos de los escritores del «Boom», pero la actitud literaria de Bolaño toma sana distancia de sus precursores latinoamericanos. El título es un oxímoron porque «detective» es un tipo específico de policía, el que practica investigaciones basadas en la deducción, y «salvaje» entre otros significados quiere decir: instintivo, incontrolado, no cultivado, primitivo ${ }^{5}$. «Salvaje», que podría ser sinónimo de «visceral», por tomar una palabra archiutilizada por el propio Bolaño, le resta a «detective» todas las connotaciones de racionalismo y orden que pudiera insinuar. Creo que el título apunta a la idea de una búsqueda desesperada que necesariamente ha de resultar infructuosa e inútil, y que se disuelve en el vacío. La figura heterodoxa del detective o del salvaje resulta una imagen del poeta. El viaje de los protagonistas al desierto de Sonora no es más que una metáfora de la estética nihilista de Bolaño: la literatura, el mundo, nosotros, todo camina hacia la disolución.

En su estructura la novela consta de tres partes que llevan los subtítulos de: Mexicanos perdidos en México (1975), Los detectives salvajes (1976-1996) y Los desiertos de Sonora (1976).

\section{Primera parte}

Está narrada por Juan García Madero, el más joven de los real visceralistas, en forma de diario, igual que la tercera parte, su continuación. En cierto modo, García Madero es una especie de alter ego de Bolaño: la utilización de la primera persona y la forma de diario invitan a tomar en cuenta esta hipótesis. Comienza esta parte en noviembre de 1975 y termina el 31 de diciembre de ese mismo año en casa de la familia Font. En las anotaciones, comprendidas en 124 páginas, se refieren episodios de una bohemia mexicana (literatura, alcohol y sexo) que nos trasladan inevitablemente al mundo de las novelas de Cortázar, principalmente Rayuela. También aquí hay un grupo de amigos apasionados por la lectura, con aficiones intelectuales y literarias, y vicisitudes amorosas. También ellos padecen la angustia existencial de una generación que no encuentra las respuestas adecuadas a sus inquietudes. Aunque hay diferencias notables: no aparece ningún Horacio Oliveira paraliza- do por preguntas metafísicas. Los personajes de Bolaño son menos especulativos, se da en ellos un instinto de supervivencia, un vitalismo que los empuja a la aventura y la acción, aunque a la postre todo resulte inútil.

García Madero es un muchacho huérfano de 17 años, estudiante de derecho, que vive con sus tíos y cuya verdadera vocación es la literatura. Está inspirado en Juan Esteban Harrington: productor audiovisual chileno que en la época del infrarrealismo tenía 15 años. Se inscribe en el taller de poesía de Julio César Álamó, en la Facultad de Filosofía y Letras, entra en contacto con los militantes de un grupo poético vanguardista, el realismo visceral, cuyos predecesores en los años veinte fueron contemporáneos de los estridentistas, y de ese modo queda integrado en la pandilla. Los verdaderos líderes del grupo son Ulises Lima, en realidad el poeta mexicano Mario Santiago, íntimo amigo de Bolaño, y Arturo Belano, chileno y alter ego del escritor; ambos llevan una vida un tanto misteriosa en esta primera parte, casi nunca están con el grupo, sólo aparecen de vez en cuando, y García Madero sospecha que viven del reparto de marihuana a domicilio.

Los demás personajes son las hermanas María y Angélica Font ${ }^{7}$, la fallecida poeta Laura Damián (un verdadero símbolo para el grupo, doble, por tanto, de Cesárea Tinajero, que sería una predecesora suya), la joven prostituta Lupe, Piel Divina ${ }^{8}$ y la pintora Catalina O'Hara'. De otra generación pero también colaborador del grupo es el padre de las hermanas Font, un arquitecto medio chiflado llamado Joaquín o Quim. ${ }^{10}$ Los real visceralistas son iconoclastas que comparten el deseo de transformar la poesía mexicana que se encontraba estancada entre el imperio de Octavio Paz y el imperio de Pablo Neruda, «entre la espada y la pared».

Cafés, bares y librerías, la casa de las hermanas Font y varios apartamentos son los lugares de reunión y puntos de encuentro del grupo. A través de los libros que roban, se muestran e intercambian podemos seguir sus preferencias literarias, por ejemplo, el Manifiesto del Movimiento Eléctrico francés (de Michel Bulteau, Matthieu Messagier y Jean-Jacques Faussot, entre otros), escritores como Alain Jouffroy, Sophie Podolski o Raymond Queneau.

Es en esta primera parte donde mejor se proyecta la imagen de la ciudad a través de los itinerarios de la pandilla ${ }^{11}$ que practicaba una

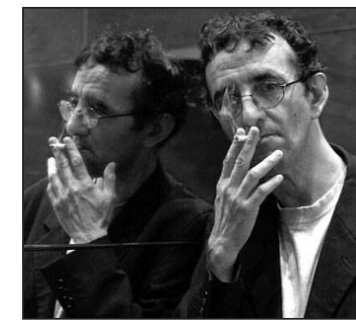

Roberto Bolaño.

5

Las dos palabras están presentes también, aunque separadas, en Los perros románticos, poemario de textos escritos entre 1980 y 1998.

Se trata de Juan Bañuelos, poeta mexicano perteneciente al grupo La Espiga Amotinada, integrado por Jaime Augusto Labastida, Eraclio Zepeda, Jaime Augusto Shelley y Oscar Oliva. Este grupo defendía posiciones políticas enmarcadas en las grandes utopías del siglo XX; denunció la pobreza y la marginación de los indígenas de México.

7

Mara Larrosa y Vera Larrosa, en la vida real.

Apodo real de Jorge Hernández, actor y realizador de performances que trabaja en París.

9

Se trata de Carla Rippey, artista visual norteamericana, fue muy amiga de Bolaño y corresponsal suya hasta poco antes de su muerte.

10

Manolo Larrosa, en la realidad, padre de las hermanas Larrosa.

11

Comentan Idez y Baigorria que la formación del grupo tuvo lugar a raíz de la expulsión de la UNAM, en 1974, por la actitud de rechazo que mantuvieron con el poeta Juan Bañuelos en el taller de poesía de Difusión Cultural de la Universidad que él dictaba: «Lejos de dispersarlos, el rechazo unió aún a los insumisos, que fijaron algunas de sus costumbres más arraigadas, como emprender caminatas interminables por México DF, leer toda la poesía que caía en sus manos y trasnochar recitando $y$ discutiendo sus textos unos con otros». (CFr. Idez y Baigorria, 2008)

En torno a Los detectives salvajes de Roberto Bolaño

CARMEN DE MORA 
12

En realidad se trata del café La Habana: «un reducto de periodistas y escritores en el que podía llegar a verse a Juan Rulfo tomándose el penúltimo tequila con Augusto Monterroso. No sólo era un lugar idóneo para conspiraciones poéticas: veinte años antes Fidel Castro le explicaba en una de esas mesas al Che Guevara cómo liberarían juntos una isla del Caribe haciendo pasar un pocillo de café por el yate Gramma». (Idez y Baigorria, 2008).

13

Amadeo Salvatierra corresponde a Rodolfo Sanabria, pintor estridentista. Poseía el único número que había aparecido de la revista Caborca dirigida por Cesárea Tinajero, ejemplar que les enseña a Belano y Lima señalándoles que es «lo único que queda de Cesárea Tinajero» (Bolaño, 1998, p. 20). En lo sucesivo citaré por esta edición). En esa misma revista figura el único poema de Cesárea, un poema hecho de líneas geométricas titulado "Sión». El hecho de que Caborca etimológicamente signifique cerrito o pequeña loma, de que esté situada al noroeste del Estado de Sonora, lugar adonde se fue a vivir Cesárea Tinajero, induce a pensar que su poema "Sión» se refiere a Caborca. Sobre todo porque Caborca es una ciudad famosa por los numerosos petroglifos que posee con diferentes formas como representaciones animales, figuras humanas, grecas, laberintos, figuras geométricas, etc. Es decir que los dibujos representados en el poema guardan cierta afinidad con los motivos de los petroglifos.

14

En 1993, en Blanes, Bolaño escribió el poema largo "Los Neochilenos» dedicado a Rodrigo Lira, el joven poeta chileno que se suicidó durante la dictadura, poema que posteriormente constituyó la segunda parte de Tres, un poemario del autor publicado en Barcelona, El Acantilado, 2000. Es un texto que recuerda el viaje a Sonora de Ulises Lima, Arturo Belano, García Madero y Lupe en Los detectives salvajes. Aquí se trata también de un viaje hacia el norte desde Santiago de Chile hacia el desierto y de allí a Perú, no en un Impala sino en una

En torno a Los detectives salvajes de Roberto Bolaño

CARMEN DE MORA

suerte de nomadismo urbano: en bares, como el «Encrucijada Veracruzana», calle Bucareli, donde solían reunirse (17 y ss.); en cafés: el café «Quito» 12 (Habana), un poco más arriba del Encrucijada, otro punto de encuentro (23); en las múltiples librerías y, por último, en las zonas y calles. La mayoría de estos lugares adquieren una connotación artística y literaria similar a la que tenía el Café en las vanguardias, al margen de la literatura institucional y en medio de la vida. Baste recordar el Sanborn's, donde se reunían los Contemporáneos, el Café París, donde se hacía la revista Letras de México, y el Europa, punto de encuentro de los estridentistas, situado en la avenida Jalisco, lugar donde se inauguró la primera exposición del estridentismo. A él le dedicó Arqueles Vela El Café de Nadie. Bolaño, en Los detectives salvajes, le hace un guiño al Europa a través del Encrucijada Veracruzana.

La originalidad de Los detectives salvajes en la recreación de la capital mexicana es que, siendo chileno el autor, consigue apresar tan bien la atmósfera de la ciudad que se diría escrita por un nativo: «Estamos ante una de las más brillantes novelas mexicanas» -ha escrito el escritor mexicano Juan Villoro (2002, p. 78.). Bolaño, en efecto, ha captado magistralmente la ciudad de los setenta, un momento histórico que forma parte del período (19501980) en que «la capital abandona su organización razonable, se extiende hasta incluir todo el Valle de México y se transforma en megalópolis o cadena de ciudades» (Monsiváis, 1985, p. 16).

El día de la cena de fin de año, de 1976, en casa de los Font, Quim, el padre de María y Angélica, decide que Belano y Lima se lleven hacia el Norte a Lupe, una joven prostituta acosada por el «padrote» (proxeneta) Alberto, quien la explota para vivir a su costa. Para favorecer la huida, pone a disposición de ellos su Ford Impala blanco. García Madero se une a ellos y así termina la primera parte. Mientras que Lupe y García Madero escapan

camioneta, pero recrea varios de los motivos que aparecen en la novela: la precariedad económica, el tráfico de drogas, los pares ("Jetachancho y Caraculo»), el fracaso y el vacío, la compañía de una prostituta que se suma cuando se dirigían hacia Lima, las referencias a los libros que leían, el azar, la superposición temporal: «El viaje comenzó un feliz día de noviembre/ Pero de alguna manera el viaje ya había terminado/Cuando lo empezamos./Todos los

del acoso de Alberto, Ulises y Arturo van, además, tras la pista de Cesárea Tinajero, la mítica fundadora del real visceralismo en los años veinte, que se encontraba en el norte del país, en los parajes desérticos del Estado de Sonora. Esta mujer, después de fundar el grupo, de editar un número, el único, de la revista Caborca ${ }^{13}$, de mudarse de la capital y de pasar una temporada en compañía de los estridentistas, había desaparecido sin dejar rastro. Mientras ellos huyen de Alberto y siguen la pista de Cesárea Tinajero, a su vez son perseguidos por Alberto. Es lo que se cuenta en la tercera parte $^{14}$ con evidentes guiños cinematográficos. Probablemente el más llamativo es el Impala blanco, un modelo de 1958 que aparece en la película American Graffiti (1973), dirigida por George Lucas, bajo la producción de Francis Ford Coppola. El film se sitúa en el verano de 1962 en que un grupo de adolescentes pasan sus últimos días juntos antes de marcharse a estudiar a distintas universidades. Rebeldes y provocadores, ante el cambio de vida que les espera, viven al límite esos últimos momentos y disfrutan de la vida en pandilla, fiestas, carreras de coches, los grandes éxitos de rock de los cincuenta, etc.

En cuanto a Cesárea Tinajero, se trata en realidad de Concha Urquiza, una poeta michoacana (1910-1945) que murió muy joven y cuya poesía ha sido relacionada con la mística y el erotismo; aunque su obra conocida es escasa se la ha comparado con los grandes poetas religiosos, como Sor Juana, por su originalidad y profundidad. Murió ahogada en las aguas de Ensenada, Baja California.

\section{Segunda parte}

La parte más extensa y ambiciosa, la segunda, de 413 páginas, es la que da título al libro, abarca veinte años y sucede en muchos lugares-México, Nicaragua, Estados Unidos, Israel, Francia, España, Angola, Austria, etc.

tiempos conviven, dijo Pancho Ferri/, el vocalista. O confluyen,/ Vaya uno a saber.» (Bolaño, 2000, p. 55). Los personajes de Bolaño en el poema, en Los detectives salvajes y en Llamadas telefónicas, entre otros textos, son seres errantes, como los ha definido su amigo Vila Matas: "seres que a mí me parece que vagan en lugares extraños, en unas afueras que no poseen un interior, como astillas a la deriva supervivientes de un todo que nunca ha existido». 
El momento axial del que surge esta parte tiene lugar en enero de 1976, cuando Amadeo Salvatierra ${ }^{15}$, el último de los estridentistas, compañero de ruta de Maples Arce, List Arzubide, Arqueles Vela, Luis Quintanilla y otros, le refiere a un interlocutor innominado la entrevista que le habían hecho Belano y Lima. Dicha entrevista discurre a lo largo de trece sesiones y en ella se encuentra prefigurada la búsqueda de los «detectives salvajes». Es más, temporalmente, coincide con el mes y el año en que los viajeros del Impala se dirigen a Sonora ${ }^{16}$. Salvatierra conserva el único ejemplar de la revista que publicó la mujer y el único poema que quedaba de su poesía: «Sión«, una línea recta, otra curva, otra quebrada y en cada una un pequeño rectángulo (un pequeño barco) ${ }^{17}$. El poema es una broma, dijeron ellos, es muy fácil de entender. Cesárea, fundadora del movimiento real visceralista, atestiguó el crepúsculo de la Revolución Mexicana y desapareció sin otro legado que su leyenda. Los restantes son testimonios en contrapunto, sobre Lima y Belano, de aproximadamente cincuenta personajes que se habían relacionado con ellos, y están planteados como si fueran respuestas a preguntas formuladas en una entrevista o en un interrogatorio policial. Pero además contienen otras muchas informaciones sustanciosas. Estos personajes están siendo interrogados porque se cree que los dos representantes del real visceralismo estaban desaparecidos, pero hay testimonios que son posteriores y tienen lugar cuando ya los dos se habían marchado a Europa.

Antes de marcharse de México, aunque Lima y Belano lograron su propósito y encontraron a Cesárea Tinajero ( «La Ítaca de esta Odisea» -como afirma Jorge Edwards) en los desiertos de Sonora, el hallazgo resultó una decepción porque la mujer, transcurrido medio siglo desde su aventura estridentista, se había convertido en una lavandera de pueblo, un personaje derrotado por la vida y enajenado, a quien, además, por una serie de malentendidos, sus propios discípulos la conducen a la muerte. Después de estos hechos, Belano y Lima regresan a la capital. El primero decide irse al extranjero, y antes de marcharse a Europa en 1977 publica una antología definitiva de la joven poesía latinoamericana. De allí se irá a África como periodista independiente, conoce al fotógrafo argentino Jacobo Urenda y acabará por perderse de nuevo en la guerra de Liberia, donde Urenda le pierde la pista.

\section{Tercera parte}

Titulada «Los Desiertos de Sonora (1976)», consta solo de 150 páginas y en ella García Madero continúa el diario en el punto en que lo dejó en la primera parte. Se narra aquí el desenlace de la huida y búsqueda emprendidas por los cuatro amigos en la línea de On the Road (1957), la novela de Jack Kerouac, de carácter autobiográfico, basada en los viajes que Kerouac y sus amigos hicieron por Estados Unidos y México, a través de la mítica carretera 66, entre 1947 y 1950. A Cesárea la localizan finalmente en Villaviciosa, un pueblucho perdido en el desierto, pero al mismo tiempo, Alberto y el policía que lo acompañaba los encuentran a ellos. En la pelea, mueren Alberto y Cesárea, y el policía resulta malherido. Después se separan los cuatro: Ulises y Arturo se marchan en el Camaro hacia el oeste, Lupe y García Madero regresan en el Impala a Villaviciosa y duermen en el cuarto de Cesárea, donde el joven poeta se hace con la herencia intelectual y poética de ella: los cuadernos de tapas negras que había ido reuniendo todos estos años; finalmente, deshacen el camino para regresar al DF. El viaje de García Madero es un viaje iniciático; él, el más joven del grupo, es el destinado a tomar el relevo generacional, a desentrañar en los cuadernos de Cesárea su legado poético y desde ahí, con toda la experiencia de vida y las numerosas lecturas asimiladas seguir avanzando. La novela termina con unas enigmáticas imágenes que el novelista no quiso aclarar.

En la configuración temporal de Los detectives salvajes alternan una linealidad apocalíptica que tiende a la disolución del mundo novelesco y un movimiento circular de eterno retorno que sugiere una especie de renovación o renacimiento. La circularidad está sugerida en los saltos temporales con retornos abruptos -el verdadero final está en el segmento 26 de la segunda parte y no en la tercera- y en la trama misma de la novela, basada en las vicisitudes de un grupo poético directamente inspirado en otro anterior que había surgido medio siglo antes. Estos nuevos real visceralistas idean incluso una revista, diseñada por Quim Font, que pretendía imitar a la Caborca de los prime-
15

Un procedimiento característico de Bolaño en esta y en otras novelas, especialmente relevante en esta segunda parte es la mezcla de personas reales con personajes ficticios: Carlos Monsiváis, Octavio Paz, Juan Marsé, quien consigue una beca de estudio para la madre enferma de Belano, Maples Arce, Verónica Volkow, bisnieta de Trostky y el poeta francés Michel Bulteau, entre otros. En la entrevista con Monsiváis (1985, pp. 160-1) el blanco de las críticas de los jóvenes es Octavio Paz, quien aparece en otros momentos de la novela, siempre en términos caricaturescos, solo comparables a los que se utiliza para caracterizar a Cesárea Tinajero.

16

Algo nada trivial, puesto que, mientras que en la entrevista salen a relucir los datos obtenidos por los real visceralistas para llevar a cabo el viaje, en la $3^{a}$ parte, por la misma fecha, se está realizando el viaje.

17

Sión es, como se sabe, una de las colinas sobre las cuales está edificada Jerusalén. El sionismo, bajo su forma mística, se manifestó durante muchos años en la creencia de que la vuelta a la tierra prometida sería obra de Dios, a través del Mesías. Creo que Bolaño juega aquí con esa tierra mítica que para los real visceralistas era Cesárea Tinajero y que resulta ser un fiasco cuando la encuentran en la tercera parte de la novela. Esto explica que cuando Amadeo Salvatierra, intrigado sin duda por el poema, les pregunta a Lima y Belano qué han sacado en claro del poema, ellos respondan sin dudar: "es una broma, Amadeo, el poema es una broma que encubre algo muy serio» (Bolaño, 1998, p. 376).

En torno a Los detectives salvajes $\mathrm{de}$ Roberto Bolaño

CARMEN DE MORA 
18

Otro detalle autorreferencial bastante irónico sobre la novela tiene lugar cuando, en París, Ulise Lima se cita con Michel Bulteau. En el testimonio de Bulteau sobre aquel encuentro, alude a una historia que le cuenta Lima y que evidentemente alude a la trama de LDS: «(...) mientras e mexicano iba desgranando en un inglés por momentos incomprensible una historia que me costaba entender, una historia de poetas perdidos y de revistas perdidas y de obras sobre cuya existencia nadie conocía una palabra, en medio de un paisaje que acaso fuera el de California o el de Arizona o el de alguna región mexicana limítrofe con esos estados, una región imaginaria o real, pero desleída por el sol y en un tiempo pasado, olvidado o que a menos aquí, en París, en la década de los setenta, ya no tenía la menor importancia. Una historia de los extramuros de la civilización, le dije» (Bolaño, 1998, p. 240). En cuanto a la circularidad está también en las continuas repeticiones con variantes que contiene la novela, por ejemplo las preguntas de métrica y retórica hechas por García Madero en la tercera parte, mientras viajan en el Impala, evocan las preguntas sobre retórica que este mismo personaje le hacía a Julio César Álamo en el taller de poesía, en la primera parte de la novela Las pesquisas en Sonora sobre el paradero y destino de Cesárea mediante preguntas a gente que supuestamente la conocieron, son paralelas a las contenidas en la segunda parte de la novela sobre Belano y Lima. El encuentro de Ulises Lima con Octavio Paz en el Parque Hundido reproduce simbólicamente el encuentro con Cesárea Tinajero en Sonora.

19

El término ya existía en el vocabulario de Mariátegui para referirse a Philippe Soupault., según señala el crítico ecuatoriano Miguel Donoso Pareja en el prólogo de la Antología Muchachos desnudos bajo el arco-iris de fuego, de los poetas infrarrealistas, publicada por R. Bolaño en 1979.

20

La antología contenía poemas de Roberto Bolaño, Mario Santiago, Bruno Montané, José Peguero, José Vicente Anaya, Rubén Medina, Cuauhtémoc Méndez y Mara Larrosa.

21

Llevaba prólogo de Miguel Donoso Pareja y epílogo de Pere Gimferrer.

En torno a Los detectives salvajes $\mathrm{de}$ Roberto Bolaño

CARMEN DE MORA ros. El anagrama de la publicación también sugiere el eterno retorno y constituye una cita autorreferencial de la novela ${ }^{18}$ : «una serpiente (que tal vez sonreía, pero que más probablemente se retorcía en un espasmo de dolor) se mordía la cola con expresión golosa y sufriente, los ojos clavados como alfileres en el hipotético lector» (Bolaño, 1998, p. 80).

\section{La proyección autobiográfica: los poetas y el mito de la vida artística en Bolaño}

Georges Duhamel en La misión de la literatura le sugiere a quien quiera ser escritor que viva intensamente la vida y que emprenda un largo viaje sin pensar en ser escritor. Estas palabras podrían servir para aproximarnos al estímulo vital que alienta la escritura del chileno, una creatividad que nace en un ámbito próximo a la experiencia para transformarse artísticamente y trascenderla. José Promis, uno de los mejores exégetas de Bolaño, considera que su literatura busca manifestar un realismo visceral, una visión interior que pugna por exteriorizarse sin claudicar frente a órdenes que no emanen de ella misma, ofreciendo, en este sentido, una construcción de la realidad alternativa y rupturista por naturaleza (Promis, 2003, p. 51). Esta actitud es la que configura Los detectives salvajes, novela basada -según es sabido- en una experiencia personal, cuando junto al poeta Mario Santiago Bolaño fundó en México el «infrarrealismo» ${ }^{19}$, movimiento dadaísta y anárquico -representado en revistas y editoriales como Correspondencia Infra, Rimband vnelve a casa o Berthe Trépat- que se transforma paródicamente en la novela en «real visceralismo». Este movimiento supuso un homenaje y un retorno a los vanguardistas de los años veinte, en particular a los estridentistas mexicanos, con quienes compartía una actitud literaria irreverente y desafiante frente a los cánones. El interés de Bolaño por este grupo data exactamente de 1976 y 1977, años en que publicó tres artículos en Plural: «Tres estridentistas en 1976: Arqueles Vela, Maples Arce, List Arzubide»; «El estridentismo» (1976) y «La nueva poesía latinoamericana: ¿Crisis o renacimiento?» (1977). El infrarrealismo representaba principalmente una mirada de admiración desde el presente hacia el período de las vanguardias en Hispanoamérica: «El momento más brillante de la literatura chilena fue cuando estaban vivos Neruda,
Pablo de Rokha y Huidobro», declaró en una entrevista. Sin embargo, en otra entrevista con la escritora mexicana Carmen Boullosa la valoración de Bolaño con el movimiento que lideró no deja de ser crítica:

El infrarrealismo fue una especie de Dadá a la mexicana. En algún momento hubo mucha gente, no sólo poetas, sino pintores y sobre todo vagos y ociosos, que se consideraron a sí mismos como infrarrealistas, pero en realidad el grupo sólo lo integrábamos dos personas, Mario Santiago y yo. Ambos nos vinimos a Europa en 1977. Después de algunas aventuras desastrosas, una noche en la estación de trenes de Port Vendres, en el Rosellón, muy cerca de Perpignan y de la estación de trenes de Perpignan, decidimos que el grupo como tal se había acabado» (Boullosa, 2002, p. 112).

A excepción del primer manifiesto (1976), de los artículos que publicó en la revista Plural, en 1976 y 1977, todos pertenecientes a Bolaño, y de las antologías Pájaros de calor. Ocho poetas infrarrealistas (1976) ${ }^{20}$ y Muchachos desnudos bajo el arco-iris de fuego. Once jóvenes poetas latinoamericanos $(1979)^{21}$, apenas existen testimonios poéticos ni personales, a pesar de que muchos de ellos sobrevivieron, como los poetas Rubén Medina, Mario Santiago y Bruno Montané.

El retorno que Bolaño lleva a cabo en Los detectives salvajes hacia la vanguardia de los años veinte y al infrarrealismo de los 70 impli$\mathrm{ca}$, salvando las distancias, una identificación con aquellas posiciones estéticas, de ahí que tanto esta novela como algunos de sus cuentos y poemas evoquen la persistencia de los principios «infrarrealistas» de juventud a que aludía Miguel Donoso Pareja en el prólogo de la antología Muchachos desnudos bajo el arcoiris de fuego. Los postulados defendidos por el escritor chileno en el primer manifiesto, en efecto, no quedan lejos de las historias ensartadas en Los detectives salvajes:

Un nuevo lirismo, que en América Latina comienza a crecer, a sustentarse en modos que no dejan de maravillarnos. La entrada en materia es ya la entrada en la aventura: el poema como un viaje y el poeta como un héroe develador de héroes. La ternura como un ejercicio de velocidad. Respiración y calor. La experiencia disparada, estructuras que se van devorando a sí mismas, contradicciones locas. (...) DÉJENLO TODO, NUEVAMENTE/LÁNCENSE A LOS CAMINOS («Déjenlo todo, nuevamente») 
(...) El riesgo siempre está en otra parte. El verdadero poeta es el que siempre está abandonándose. Nunca demasiado tiempo en un mismo lugar, como los guerrilleros, como los ovnis, como los ojos blancos de los prisioneros a cadena perpetua ${ }^{22}$.

Los infrarrealistas se acercaron también a dos grupos vanguardistas de los 60 y 70 : el ecuatoriano de «Los Tzántzicos» (19601969), que practicaron una poesía combativa y revolucionaria, y el peruano «Hora Zero» (1971), cuyo lema era "construir lo nuevodestruir lo viejo».

Aunque posteriormente Bolaño se inclinara a reducir aquel movimiento «infrarrealista» a una diversión o entretenimiento poético de juventud, es indudable que en esos años se gestaron los rasgos fundamentales de su poética y de su práctica literaria, y ellos constituyen la fuente de la historia contada en Los detectives salvajes. Pero, sobre todo, a partir de aquella experiencia el mito del poeta, «aquel que camina hacia el abismo por su propia voluntad», en cuanto individuo marginal que escribe fuera de la ley o contra la ley, y de la vida artística se incorporaron a su obra. En el discurso pronunciado en Caracas, cuando recibió el premio Rómulo Gallegos, reconoció:

En gran medida todo lo que he escrito es una carta de amor o de despedida a mi propia generación, los que nacimos en la década del 50 y los que escogimos en un momento dado el ejercicio de la milicia, en este caso sería más correcto decir la militancia, y entregamos lo poco que teníamos, lo mucho que teníamos, que era nuestra juventud, a una causa que creímos la más generosa de las causas del mundo y que en cierta forma lo era, pero que en la realidad no lo era (Bolaño, 2008, p. 40).

\section{El género policial como «architexto» de la novela}

A imitación de Poe, Borges y tantos escritores del siglo XX, Bolaño recurre a la estrategia hermenéutica del policial en la mayoría de sus novelas. Sin embargo, no basta relacionarlo sin más con este género; de un lado, el lector de novelas policiales se encuentra en los libros de Bolaño en una situación de precariedad, buscando afanosamente un sentido en los hechos narrados que el texto se niega a facilitar. A semejanza de las novelas kafkianas, parece que hubiera un enigma a desvelar, un secreto que el texto finge esconder, una inminencia que finalmente no se produce. De otro, entre los personajes de Bolaño la figura dominante del poeta o del escritor es un investigador heterodoxo de lo real, un detective salvaje cuyas búsquedas se disuelven en la nada. Por tanto, sin olvidar la exploración de las vinculaciones entre la literatura y el mal -otro tema recurrente en la obra del chileno susceptible de conectarse con el género negro-, lo policial en Bolaño podría considerarse, desde mi punto de vista, una estrategia de escritura y de lectura que, desvinculada del razonamiento deductivo original, y precisamente por ello mismo, dejaría en evidencia la estética nihilista del escritor. Carlos Franz, uno de los mejores escritores chilenos actuales, refiriéndose a 2666, traduce el pensamiento nihilista de Bolaño en términos de un pesimismo esencial, de una profunda melancolía: «(...) la literatura, al igual que nosotros, al igual que el mundo, va derecho hacia ese matadero en el desierto que es Santa Teresa. (...). Por tanto toda acción es inútil, ya que la literatura -y con ella los escritores- están destinados solamente a los desiertos (que es como decir a los osarios) de Sonora, es decir, al matadero. Olvido, extinción, desaparición en vida por la falta de lectores -como no sean los lectores otros escritores» (Franz, 2008, pp. 106 y 107).

\section{¿Qué hay detrás de la escritura de Bolaño?}

Los detectives salvajes termina con una pregunta «¿Qué hay detrás de la ventana?» y un dibujo con un cuadrado vacío de trazado discontinuo. En retórica, constituye un «dubbio», esto es, una pregunta final dirigida al lector o a un interlocutor interno, una invitación a juzgar o interpretar lo narrado.

Algunas reflexiones pueden contribuir a despejar el enigma. Esta novela, igual que el resto de la narrativa de Bolaño, se inscribe en el llamado posmodernismo cultural. La comparación, siquiera superficial, con Rayuela permite apreciar la diferencia de las nuevas producciones literarias con respecto a la narrativa del Boom. En Raynela existía un desmantelamiento de la tradición: de la metafísica tradicional, del género novela, del papel del lector, de las limitaciones del lenguaje, entre otros aspectos. La aspiración de la búsqueda era en Rayuela el centro del mandala, el cielo de la rayuela, el kibbuts, el Iggdrassil, la Edad de Oro, el Edén, la Arcadia, etc., metáforas con las que se aludía a una realidad utópica
22

El manifiesto, redactado enteramente por Bolaño, fue publicado en la revista INFRA ○ Revista Menstrual del movimiento Infrarrealista. Octubre-Noviembre de 1977. Ciudad de México. Javier Campos cita también como integrantes a José Peguero, Bruno Montané, Rubén Medina, Carlos David Malfavón, Javier Suárez Mejía y Mario Santiago. Para Campos, el manifiesto «no es otra cosa que un reprocesamiento actualizado, en esos 70, de toda la poética surrealista de comienzos del siglo 19 y principios de 20 más la fuerte influencia de dos grupos vanguardistas latinoamericanos de los 60 y 70 . Primero era el grupo ecuatoriano llamado «Los Tzántzicos» (1960-1969), nombre tomado de los indígenas reducidores de cabezas de la selva amazónica, «Los Tzántzicos» hicieron una poesía de denuncia combativa y revolucionaria pero se negaron a publicar poemas puesto que serían destinados a satisfacer el gusto de capas sociales élites e insensibles (...). El segundo era el grupo peruano «Hora Zero» que en 1971 se definía como "construir lo nuevodestruir los viejo». O sea, no había mucha diferencia en ambos grupos realmente -aunque mucho más vanguardista radical eran «Los Tzántzicos»- que luego Bolaño readaptó e incorporó en el manifiesto construyendo una poética reprocesada que él llamó «infrarrealista». De allí que Ulises Lima venga a ser claramente en la novela un poeta cien por cien «tzántzico». En otras palabras, el poeta infrarrealista debía subvertir lo cotidiano a través de una imaginación igualmente subversiva para descubrir mundos nuevos. E poeta debía ser un francotirador, un aventurero. Debía tener otra manera de mirar, opuesta a la mirada complaciente del arte burgués. El poeta debía fijarse en lo diverso del mundo, especialmente en la diversidad de la urbe y asimilarla a su poesía» (Campos, 2006).

En torno a Los detectives salvajes de Roberto Bolaño

CARMEN DE MORA 


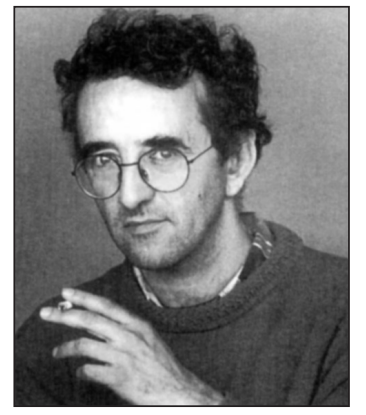

Roberto Bolaño.

23

El destino de García Madero -y con él de los cuadernos de Cesárea- y Lupe no se conoce. Ella quería quedarse en Sonora o marcharse a algún lugar de Estados Unidos, pero nada vuelve a decirse de ellos en la novela.

24

Idelber Avelar relaciona directamente la situación de la literatura postdictatorial con la experiencia de la derrota histórica: "La irreductibilidad de la derrota es para Piglia, Santiago, Eltit, Noll y Mercado, el fundamento de la escritura literaria. Todos ellos escriben bajo la conjunción de dos determinaciones fundamentales, el imperativo del duelo y la decadencia del arte de narrar» (Averlar, 2000, p. 34).

En torno a Los detectives salvajes de Roberto Bolaño

CARMEN DE MORA ansiada por todos. En muchos sentidos Bolaño es un neovanguardista, como Cortázar, que adopta como premisa de su narrativa la transgresión, pero aquellos referentes con que contaba Cortázar ya no asoman en Bolaño sino parodiados, porque aquí la utopía -Cesárea Tinajero- se ha transformado en un personaje grotesco, y el encuentro con ella, en un desencanto parricida. El nivel de la enunciación se sostiene con frecuencia sobre voces que han perdido su seguridad narrativa o sobre un dialogismo discursivo que puede resultar contradictorio. Incluso la presentación, en la primera parte de la novela, de los real visceralistas como un grupo de poetas y artistas con intereses afines, resulta un espejismo, ya que, sin razones explícitas, Ulises Lima lleva a cabo por su cuenta una purga que irrita a los expulsados y genera enemistades que terminarán por disolverlo. Todo en la novela produce una visión caótica y desesperanzada de la realidad que desprende una gran melancolía.

Y, no obstante, esta visión, o, mejor dicho, la voluntad de dar cuenta de esta visión, constituye el fundamento de la escritura y la origina. En las producciones del final del milenio el caos se considera más fecundo que el orden, la incertidumbre se prefiere antes que lo predecible y la fragmentación se considera más real que la unidad. «Entre más nos acercamos al final del siglo XX -afirmó Luz Mary Giraldo- las artes muestran el espíritu errante del vacío y las expresiones lo manifiestan como consigna y espíritu de nuestro tiempo. Los escritores dan testimonio de la pérdida del centro y la prevalencia del vacío» (Giraldo, 2000, p. 36). La inclinación a romper límites, testimoniar la despersonalización y el desarraigo en los espacios urbanos, recurrir a distintos tipos de discursos, recuperar las estéticas del pasado bajo la parodia, desterrar el idealismo ingenuo y el romanticismo engañoso de la vida cotidiana, manifestar el desencanto de las utopías y el mundo acelerado en que nos ha tocado vivir, así como la metaficción o autoconciencia literaria, son rasgos de la estética de Bolaño que comparte con otros muchos escritores del final del milenio.

En cuanto a la composición, conforme se avanza en el proceso narrativo aumenta la resistencia al paradigma de las expectativas (Kermode, 2000, pp. 27 y ss.): además de burlar la inercia propia de la linealidad y la continuidad temporal o la estabilidad espacial, deja sin responder las numerosas preguntas que suscita en el lector. Así, éste no podrá saber en detalle qué fue de los real visceralistas que sobrevivieron, adónde fueron a parar García Madero y Lupe, cuál era el contenido de los cuadernos de Cesárea custodiados tras su muerte por el joven García Madero, qué significado tiene el poema de Cesárea, o las ventanas que cierran la novela, etc. ${ }^{23}$. Tales características ponen de manifiesto que el texto está escrito desde el escepticismo y la desconfianza sobre las posibilidades del arte de narrar.

Ahora bien, existe un trasfondo histórico y político de derrota, representado en la novela por el golpe de estado en Chile y la matanza de la plaza de Tlatelolco que ayuda a entender en parte la crisis que viven los personajes y el vacío de sus vidas. Hechos aquellos que no deben considerarse aislados sino como manifestaciones del horror vivido por varios países latinoamericanos en la segunda mitad del siglo XX. Así, aunque aquellos sucesos no constituyan el centro de la novela, la determinan. La escritura de Bolaño comparte con la de otros escritores latinoamericanos actuales su naturaleza postdictatorial, la aceptación de la derrota como determinación de la escritura literaria en Latinoamérica. En toda su narrativa parece recordar una y otra vez aquella conocida frase de Walter Benjamín «Jamás se $\mathrm{da}$ un documento de cultura sin que lo sea a la vez de la barbarie» (Benjamin, 1989, p. 182), y la coloca en la perspectiva de la historia latinoamericana que se inicia hacia fines de los sesenta (con la represión de los estudiantes en el México de 1968) y desemboca en los genocidios de la década del setenta en Chile, Argentina y en otros países. El logro radica en haber sabido incorporar el contexto histórico latinoamericano a sus novelas mediante un proceso de representación simbólica y ficcionalización sin caer en la facilidad de una literatura testimonial.

El mundo de la novela es, por tanto, uno en el que las ilusiones se han derrumbado tanto por los traumas políticos del siglo $\mathrm{XX}$, como por el fracaso de los ideales revolucionarios. Y con ellas también la confianza en el papel de la ficción ${ }^{24}$. Es ese telón de fondo el que ayuda a entender en buena medida la vida sin metas de los personajes: la literatura se convierte para ellos en una tabla de salvación que sin embargo 
no les servirá para mantenerse a flote por mucho tiempo.

Los finales de las tres partes de la novela resultan esclarecedores para la lectura. El final de la primera parte y el final de la tercera no son muy distintos: en el primero, el joven García Madero vuelve la cabeza hacia atrás y mira por la ventanilla mientras el Impala avanza; en el segundo, mientras conduce el Impala le pregunta a Lupe «¿qué hay detrás de la ventana?». Ese mirar hacia atrás mientras se avanza se corresponde con la caracterización que hace Ulises Lima de los real visceralistas, en las primeras páginas de la novela, al afirmar que caminaban hacia atrás: «De espaldas, mirando un punto pero alejándonos de él, en línea recta hacia lo desconocido" (Bolaño, 1998, p. 17). Viene al caso relacionar este leitmotiv de unos personajes que avanzan mirando hacia atrás -que representa, en suma, la actitud del escritor en la novela- con el comentario que hace Walter Benjamín de un cuadro de Klee llamado Angelus Novus en su Tesis de filosofía de la historia:

En él se representa a un ángel que parece como si estuviese a punto de alejarse de algo que le tiene pasmado. Sus ojos están desmesuradamente abiertos, la boca abierta y extendida las alas. Y este deberá ser el aspecto del ángel de la historia. Ha vuelto el rostro hacia el pasado. Donde a nosotros se nos manifiesta una cadena de datos, él ve una catástrofe única que amontona incansablemente ruina sobre ruina, arrojándolas a sus pies. Bien quisiera él detenerse, despertar a los muertos y recomponer lo despedazado. Pero desde el paraíso sopla un huracán que se ha enredado en sus alas y que es tan fuerte que el ángel ya no puede cerrarlas. Este huracán le empuja irrefrenablemente hacia el futuro, al cual da la espalda, mientras que los montones de ruinas crecen ante él hasta el cielo. Ese huracán es lo que nosotros llamamos progreso (Benjamin, 1989, p. 183).

Kafka, en su Diario (28 de enero de 1922) recuerda que para él los hombres no tienen otra elección que ésta: o buscar la Tierra prometida del lado de Canaán, o buscarla del lado de este otro mundo que es el desierto, "ya que no existe para los hombres una tercera región» (Kafka, 1953, p. 394). Bolaño fundió las dos opciones de Kafka y situó la Tierra prometida en el desierto; así lo hizo en dos de sus obras mayores, Los detectives salvajes y 2666.

\section{Bibliografía}

Avelar, Idelber (2000), Alegorías de la derrota: la ficción postdictatorial y el trabajo del duelo, Santiago, Editorial Cuarto Propio.

Benjamin, Walter (1989), «Tesis de filosofía de la historia», en Discursos interrumpidos I, Madrid, Altea, Taurus, Alfaguara.

Bolaño, Roberto (1998), Los detectives salvajes, Barcelona, Anagrama.

- (2000), Tres, Barcelona, El acantilado.

- (1977), «Manifiesto algo», INFRA o Revista Menstrual del movimiento Infrarrealista. Octubre-Noviembre de 1977. Ciudad de México.

- (2008), «Discurso de Caracas», en Edmundo Paz Soldán y Gustavo Faverón Patriau (eds.), Bolaño salvaje, Barcelona, Editorial Candaya.

Boullosa, Carmen (2002), «Carmen Boullosa entrevista a Roberto Bolaño», en Celina Manzoni (Compilación, prólogo y edición), Robeto Bolaño. La escritura como tauromaquia, Buenos Aires, Ediciones Corregidor.

Campos, Javier (2006), «El Primer Manifiesto de los Infrarrealistas' de 1976: su contexto y su poética en Los detectives salvajes», Crítica. cl. Revista digital de crítica, ensayo e Historia del arte. Publicado el 06/12/2006: http://critica.cl/literatura/elprimer manifiesto-de-los-infrarrealistasde-1976-su-contexto-y-su-poetica-en-losdetective-salvajes-1. Consultado el 16 de febrero de 2011.

Franz, Carlos (2008), "Una tristeza insoportable'. Ocho hipótesis sobre la mela-cholé de $\mathrm{B}$ », en Bolaño salvaje, Barcelona, Editorial Candaya.

Giraldo, Luz Mary Giraldo (2000), «Fin del siglo XX: por un nuevo lenguaje» (19601996), en Jaramillo, María Mercedes, Osorio, Betty y Robledo, Ángela I. (compiladores), Literatura y cultura. Narrativa colombiana del siglo $X X$. Diseminación, cambios desplazamientos, vol. 2, Colombia, Ministerio de Cultura.

Idez, Ariel y Baigorria, Osvaldo (2008), «La pandilla salvaje», Página/12. Radar, Domingo, 10 de Agosto de 2008. Consultado en Internet el 16 de febrero de 2011: http://www.pagina12.comar/diario/suplementos/radar/9-4753-2008-08-10.html

Kafka, Franz (1953), Diarios 1910-1923. Compilación de Max Brod. Traducción

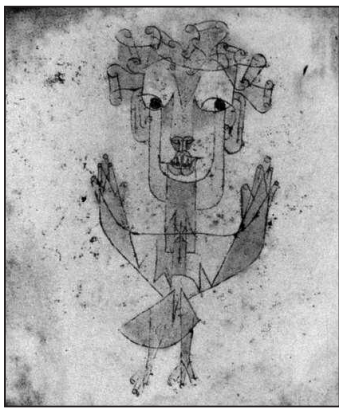

Angelus Novus de Paul Klee.
En torno a Los detectives salvajes $\mathrm{de}$ Roberto Bolaño

CARMEN DE MORA 
de J.R. Wilcock. Buenos Aires, Emecé Editores, S.A.

Kermode, Frank (2000), El sentido de un final, Barcelona, Editorial Gedisa, S.A.

Manzoni, Celina, Gras, Dunia, Brodsky, Roberto (2005), Jornadas homenaje a Roberto Bolaño (1953-2003): Simposio internacional, Barcelona, ICCI Casa Amèrica a Catalunya.

Monsiváis, Carlos (1985), «La Ciudad de México: un hacerse entre ruinas», en $E l$ Paseante, 15-16, Madrid.

Pollack, Sarah (2009), «Latin America Translated (Again): Roberto Bolaño's The
Savage Detectives in the United Status», Comparative Literature, Duke University Press, 61, pp. 346-365.

Promis, José (2003), «Poética de Roberto Bolaño», en Patricia Espinosa H., Territorios en fuga. Estudios críticos sobre la obra de Roberto Bolaño, Santiago, Frasis Editores. Villoro, Juan (2002), «El copiloto del Impala», en Celina Manzoni (compilación, prólogo y edición), La escritura como tauromaquia, Buenos Aires, Ediciones Corregidor.

Fecha de recepción: 03/07/2011

Fecha de aprobación: 18/10/2011 